\title{
A Summary of Teaching Reform of Software Engineering Major Under the Background of Big Data
}

\author{
Jianjun Huang ${ }^{1, \mathrm{a}}$, Weiwei Gong ${ }^{1, \mathrm{~b}}$ and Rongqun $\mathrm{Hu}^{1, \mathrm{c}}$
}

\author{
${ }^{1}$ School of Computer Information Engineering, Nanchang Institute of Technology, Nanchang, Jiangxi, China \\ ahuangjianjun@nut.edu.cn, bongweiwei@nut.edu.cn, ${ }^{\mathrm{b}}$ hurongqun@nut.edu.cn
}

\begin{abstract}
With the continuous development of science and technology, computers have been widely used, big data is a topic of great concern. The advent of the era of big data has greatly improved people's ability to analyze and process data, the convenience brought to people's lives is obvious to all. The healthy development of big data industry can not be separated from the support of software engineering professionals with high comprehensive quality, in order to train more high-quality software engineering professionals in the background, the reform and innovation of software engineering teaching is needed, which also adapts to the development direction of software engineering major.This paper summarizes the views of Li Yuefei, Wang Yichao, Wang Rei, Xiu Xiaoyu, Peng Zhengquan, Fang Yujie and other scholars, starting from the background of the research background of the teaching reform of software engineering in the context of big data, and makes a key analysis of the reform of software engineering professional model in the background of big data.
\end{abstract}

Keywords: big data, software engineering, talent training, reform

\section{RESEARCH SOFTWARE PROFESSIONAL \\ BACKGROUND OF ENGINEERING UNDER THE BACKGROUND OF BIG DATA}

With the continuous development of the times, now the data and intelligence has become an important reason to affect people's daily life. The most accurate data is necessary for all walks of life to develop better. Although China attaches great importance to the development of big data industry in the process of development, but because China started late in this area, the actual experience is not rich, and under the influence of the big data era, the demand for talents in all walks of life in China has also changed. Among them, the demand for talents in the field of software engineering is greatly increased. For enterprises, software engineering professionals must have a solid theoretical foundation, but also have certain research and development capabilities. In the specific work process, they can combine their theoretical foundations with reality to develop more Good software [2]. In the process of education, due to the influence of traditional educational concepts, most colleges and universities only involve knowledge theory in teaching, and do not pay much attention to improving students' abstract processing ability. However, in the actual work process, if the student does not have good abstract processing ability, then the student will not be able to visualize some abstract theoretical knowledge, which will have a more serious impact on future work. In this regard, relevant institutions should focus on exploring the reform of software engineering talents, further increase cooperation between schools and enterprises, and form a two-way talent training model so that they can cultivate the best talents for the society [2].

\section{TEACHING STATUS OF SOFTWARE ENGINEERING MAJORS UNDER THE BACKGROUND OF BIG DATA}

The core of software engineering course teaching is to train a batch of professional network data knowledge, with the continuous improvement of the level of basic education, the community's requirements for software engineering professionals are gradually improving. The teaching materials used in the teaching of the existing software engineering courses are not close enough with the background of big data, nor can they accurately reflect the technical characteristics of the industry. In the context of the era of big data, the teaching of software engineering courses should be closely integrated with the actual needs of the society, discarding the old and outdated parts of the existing teaching materials, and applying the appropriate Internet big data means to add more interest to the boring curriculum teaching. At this stage, the teachers of software engineering teaching, most of them do not have a very high level of professional skills, they generally rely on their own years of teaching experience to teach students knowledge.

\section{SOFTWARE ENGINEERING CONSTRUCTION IN THE AGE OF BIG DATA}

The era of big data requires software engineering professionals with big data thinking, broader and more solid knowledge, with stronger learning ability, practical ability and innovation awareness. In the era of big data, the positioning, training objectives, training measures, teaching methods and learning methods of software engineering professionals need to be adjusted or refactored[6]. 


\subsection{Updating and Enriching Training Goals and Training Programs}

The era of big data requires professionals with rapid response, keen observation and comprehensive analytical skills, emphasizing hands-on and innovation. For the software engineering professional for big data, the training goal includes not only the knowledge, skills and methods of the relevant software engineering needed to be understood and mastered by the traditional software engineering major, but also familiar with the big data technology framework and ecosystem, master the architectural principles and use scenarios of big data, and familiar with the relevant skills and methods such as data processing and analysis. The curriculum system of software engineering major sits on the basis of the original curriculum system and resources, but also needs to add big data, data analysis and mining, Hadoop, NoSQL, data warehouse and other courses and resources.

In the era of big data, teachers can make full use of big data knowledge in the teaching process to analyze all aspects of students' information, grasp the students' learning situation, learning attitude, software development level and knowledge ability. The advantage of big data of teaching methods is that teachers can use this way to help students make long-term learning plans, ensure the subjectivity of students in the teaching process, give full play to the initiative of students' learning, and stimulate students' desire to study. In the course of teaching, new teaching methods are introduced, the teaching process is optimized by choosing to flip the classroom, micro-course, and learn the teaching as the center, emphasizing personalized learning, fragmented learning, collaborative learning and timely feedback. Assessment can not only be reflected in the score, but need to multi-evaluation, improve the teaching effectiveness and quality [1].

\subsection{Strengthening the Construction of the Teaching Staff}

The development of software talents needed in the era of big data must have a high level of innovative software engineers. Teachers must not only understand the knowledge and technology of software engineering, but also understand the concepts, theories and technologies of big data technology, and apply big data technology to software engineering teaching. At the same time, they also need to use big data analysis technology to analyze students' learning behaviors, homework and exams, master the students' learning status, and provide personalized guidance. As the research and application of big data technology in China has just started, the teachers who master big data technology and application in colleges and universities are not only lacking, but also have few practical experience. Therefore, the construction of a title structure, academic structure, age structure, academic structure reasonable "double division" teachers, professional construction and sustainable development is very important. Through the "training, introduction, promotion" and other measures, the selection of young and middle-aged teachers to the relevant universities, enterprises to further education, improve the knowledge structure of teachers big data, practice level and application ability; Through the "cultivation, introduction, promotion" and other measures, young and middle-aged teachers must be selected to go to relevant universities and enterprises for further study, to improve the knowledge structure, practical level and application ability of teachers' big data; To introduce experienced engineers in the enterprise as external teachers and enrich the teaching staff [5].

\subsection{Focus on Application Ability and Innovative Thinking Training}

In the era of big data, innovation and application is the driving force to realize the social value and economic benefit of big data. The software talents trained by software engineering specialty are the main force in developing and processing the application system of big data. In the era of big data, the enterprise application system should not only have the basic functions of Data Management, Statistics and query, but also have the powerful function of data analysis. Therefore, the software talents who deal with and apply big data must have strong application ability and innovative thinking to solve practical problems. The main way to cultivate the application ability is to participate in the analysis and development of practical application projects under the guidance of enterprise engineers or teachers with rich practical experience. Enterprises can provide experienced application engineers and practical application projects, school-enterprise cooperation is an important way to cultivate the application ability of Software Talents[3].

It is necessary to pay attention to the reconstruction of the training system and the training platform, because for the software engineering students, improving the programming level is the most important, and the training on the computer can not be ignored. In addition to the traditional training environment, software engineering in the context of big data should also set up an experimental platform and practice base with big data. In the specific practical teaching process, teachers not only want to make students to master the relevant big data key technologies and processes, but also to explain the relevant technical problems, encourage students to carefully analyze the problem and guide them to find solutions to the problem. Practical training projects should be combined with real business cases, training students to solve problems independently. We should also seek partners to build training bases with enterprises, establish collaborative innovation concepts, stimulate students and independent innovation, and tap students' potential and expertise.

\subsection{Focus on Personalized Learning}

With the rapid development and wide application of mobile Internet technology and big data technology, personalized push and learning anytime, anywhere is possible [5]. In the era of big data, more attention should be paid to teaching students in accordance with their aptitude, individualized training, and individual differential development and success. The era of big data will be learner-centered, realize personalized learning based on big data analysis, use big data technology and intelligent algorithms to analyze each student's learning situation, according to the students reflect in the learning problems, targeted push learning content and 
Chinese)

[6] Fang Yujie, "Thoughts on the Construction of Software Engineering Majors in the Age of Big Data, Science and Technology Information," 2019, Issue 6, 34-36. (In Chinese)

\section{CONCLUSION}

In addition to the description of the amount of data, big data also reflects the efficiency of data processing. This is an important factor affecting social production, because the ability to mine data affects the competitive advantage in the market. In order to bring out the advantages of big data, the technological innovation alone is far from enough, high-quality software and talents are also essential.

In short, in the era of big data, enterprises need more professional and innovative application-oriented software talents, while education needs to be reformed in teaching, which is an inevitable trend. Therefore, education reform needs to be deepened continuously In all sorts of ways. This paper analyzes the teaching reform from the aspects of teaching content, teachers and teaching methods, hoping to provide reference for the talent training and social development under big data.

\section{REFERENCES}

[1] Li Yuefei, "On the Teaching Reform of Software Engineering Major in the Age of Big Data," Rural Economy and Technology, 2017, Issue 24, 29-20. (In Chinese)

[2] Wang Yichao, "Reflections on the Construction of Software Engineering Majors in the Age of Big Data," Zhifu Times, 2018, Issue 8, 90-91. (In Chinese)

[3] Wang Rui, "Analysis of Teaching Reform of Software Engineering Majors in the Age of Big Data," Digital Design, 2018, 2, 11-12. (In Chinese)

[4] Xiu Xiaoyu, "Teaching Reform of Software Engineering Major under the Background of Big Data," information technology era, mid-term, 2019, Issue 1, 56-57. (In Chinese)

[5] Peng Zhengquan, "Analysis of Teaching Reform of Software Engineering Major under the Background of Big Data," Science and Wealth, 2019, Issue 23, 53-53. (In 